are no clinical data showing that the use of toremifene in place of tamoxifen would reduce the incidence of endometrial cancer. Orion Pharma should rethink its marketing strategy.

CHRIS TWELVES Senior lecturer in medical oncology ADRIAN HARNETT

Beatson Oncology Centre, Consultant clinical oncologist Glasgow G11 6NT

1 Friedman MA, Trimble EL, Abrams JS. Tamoxifen: trials, tribulations and trade-offs. $\mathcal{F}$ Natl Cancer Inst 1994;86: 478-9.

2 Fisher B, Costantino JP, Redmond CK, Fisher ER, Wickerham DI, Cronin WM. Endometrial cancer in tamoxifen-treated breast cancer patients: findings from the national surgical adjuvant breast and bowel project (NSABP) B-14. $g$ Nat Cancer Inst 1994;86:527-37.

3 Hayes DF, Van Zyl JA, Hacking A, Goedhals L, Bezwoda WR, Mailliard JA, et al. Randomized comparison of tamoxifen and two separate doses of toremifene in postmenopausal women with metastatic breast cancer. $尹$ Clin Oncol 1995; 13:2556-66.

\section{Manufacturer's reply}

EDITOR,-Naturally we are concerned that Chris Twelves and Adrian Harnett take exception to our advertisement for Fareston (toremifene). Yes, the advertisement focuses on patients concerns, but are they not relevant? It is not surprising that some women diagnosed as having breast cancer are concerned by what they have read or heard about tamoxifen. Debate in the medical press, ${ }^{12}$ sensationalism in the lay press, and the information superhighway mean that women are more aware of the issues than ever before.

Twelves and Harnett focus exclusively on endometrial cancer, and yet the advertisement makes no mention of endometrial cancer. Clearly this subject is uppermost in their thoughts because of the debate that has been stimulated on it, but what other issues concern patients? The cancer charity Tenovus has recently published a booklet entitled Tamoxifenthe facts. ${ }^{3}$ The publication covers the 20 questions that are most commonly asked about tamoxifen. These include "Does tamoxifen cause cancer of the womb (uterine cancer)?" and "Does tamoxifen cause liver cancer?"

Our advertisement for toremifene does not sensationalise the issue; it simply acknowledges and reflects the situation that exists. It does not make any claim for toremifene over tamoxifen with regard to endometrial cancer for the reasons outlined. The advertisement states, however, that toremifene does not cause DNA adducts and is not hepatocarcinogenic in rats-which is in total contrast to tamoxifen. ${ }^{4}$ The clinical relevance of this in patients is not yet determined. Nevertheless, this is an important preclinical difference between the two products that to the best of our knowledge has not been studied clinically in sufficient detail. This absence of evidence is not the same as there being no evidence of effect, and thus the experience with tamoxifen is irrelevant here.

Toremifene offers, for the first time, an alternative to tamoxifen for first line hormonal treatment of hormone dependent metastatic breast cancer in postmenopausal patients Doctors will have to decide the most appropriate treatment, bearing in mind the principle outlined in the Calman report that "Patients, families and carers should be given clear information and assistance in a form they can understand about treatment options and outcomes available to them at all stages of treatment from diagnosis onwards."
King CM. Tamoxifen and the induction of cancer. Carcinogenesis 1995;16:1449-54.

2 Bulbrook RD. Long term adjuvant therapy for primary breast cancer. $B M{ }^{\prime}$ 1996;312:389-90.

3 Tenovus. Tamoxifen - the facts. Cardiff: Tenovus, 1996.

4 Hard GC, Iatropoulos MJ, Jordan K, Radi L, Kaltenberg OP Imondi AR, et al. Major difference in the hepatocarcinogenicity and DNA adduct forming ability between genicity and DNA adduct forming ability between
toremifene and tamoxifen in female CR1:CD(BR) rats. toremifene and tamoxifen in
Cancer Res 1993;53:4534-41.

5 Expert Advisory Group on Cancer. A policy framework for commissioning cancer services. A report to the chief medical officers of England and Wales. London: Department of Health, 1995.

\section{Community pharmacists are increasingly supervising treatments}

EDITOR,-Louise Sell and colleagues draw attention to the fact that community pharmacists are an underused resource in ensuring compliance in the treatment of drug dependence and tuberculosis. ${ }^{1}$ They note that community pharmacists have expressed willingness to supervise the consumption of methadone; in Glasgow this willingness has been translated into practice. In early 1994 a fifth of the 214 community pharmacies in Glasgow were supervising the administration of methadone. ${ }^{2}$ This proportion has now reached three fifths, and over $70 \%$ of all methadone dispensed in these pharmacies is now supervised. During 1995 the consumption of over 300000 doses of methadone was supervised in the community pharmacies in Glasgow. The Royal Pharmaceutical Society of Great Britain has now produced preliminary guidelines on supervised self administration of methadone. ${ }^{3}$

Many pharmacists have expressed their willingness to extend this service to other therapeutic areas, and to our knowledge treatment with other medicines (for example, benzodiazepines and dihydrocodeine) and for other conditions (for example, Alzheimer's disease) is being supervised.

The benefits to patients as well as for pharmacists and society at large clearly point to this being an appropriate use of a valuable professional resource. We have already been contacted about this service by an appreciable number of drug treatment services throughout England, and we would welcome further contacts.

COBERT SCOTT Clinical director HOWARD MCNULTY

Glasgow Drug Problem Service, Chief area pharmaceutical officer

Ruchill Hospital,

Glasgow G20 9NB

1 Sell L, Finch E, Farrell $M$, Sheridan J, Strang J. Directly observed treatment for tuberculosis. BMF 1996;313:45. (6 July.)

2 Scott RTA, Burnett SJ, McNulty H. Supervised administration of methadone by pharmacists. $B M F$ 1994;308:1438.

3 Royal Pharmaceutical Society of Great Britain Scottish Department Executive. Pharmaceutical services to drug misusers: supervised self administration of methadone within misusers: supervised self administration of methadone within RPSGB, 1995.

\section{Septic arthritis in osteoarthritic hips}

\section{Authors' interpretation of radiograph was} wrong

EDITOR,-D J Knight and colleagues report the development of septic arthritis in osteoarthritic hip joints. ${ }^{1}$ They state that the radiograph in figure 1 in their paper shows an osteoarthritic right hip and that that in figure 2 shows the subsequent changes of septic arthritis. In figure 1 the femoral head is flattened, and there is extensive destruction of subarticular bone. The joint space is narrowed, with evidence of a joint effusion with bulging of the lateral fat plane. The acetabular roof is osteopenic, and there is erosion of the medial acetabular margin. The radiological findings are those of a septic arthritis and not osteoarthritis as stated by the authors. ${ }^{2}$ The destructive process has progressed by the time of the radiograph shown in figure 2 .

D C HOWLETT Radiologist

$X$ Ray Department, St Thomas's Hospital, London SE1 7EH

Knight DJ, Gilbert FJ, Hutchinson JD. Septic arthritis in osteoarthritic hips. BMf 1996;313:40-1. (6 July.)

2 Renton P. Periosteal reaction; bone and joint infections, sarcoid. In: Sutton D, ed. A textbook of radiology and imaging. 5th ed. London: Churchill Livingstone, 1993:52-4.

\section{Authors' reply}

EDIToR,-Despite D C Howlett's comments we believe that the changes in our figure 1 are compatible with a diagnosis of osteoarthritis. There is appreciable narrowing of the joint space, with deformity of the femoral head and cystic changes - all signs of osteoarthritis. Also, the second $x$ ray film was obtained seven months after the first, and an infective process would be expected to progress more rapidly. Furthermore, we believe that the lateral fat plane sign mentioned by Howlett is unreliable as a sign of disease of the hip joint, especially in adults. ${ }^{1}$

We believe that the basic lesson of our paper remains. The clinical picture and the $x$ ray changes of osteoarthritis and septic arthritis overlap, and infection may be missed if it is not considered.

F J GILBERT Professor of radiolog D J KNIGHT

Aberdeen Royal Infirmary

Consultant orthopaedic surgeon

Aberdeen AB9 2ZB

J D HUTCHISON

University of Aberdeen

Professor of orthopaedic surgery Aberdeen AB9 1FX

1 Resnick D, Niwayama G. Anatomy of individual joints. In Diagnosis of bone and joint disorders. 2nd ed. Philadelphia: W B Saunders, 1988:712-3.

\section{More emergency insulin distribution projects should be set up}

EDrror,-The International Diabetes Institute and the supporters of its emergency insulin distribution project are encouraged by $J$ Burdon's personal view detailing how this project has helped diabetic patients in rural Zaire. ${ }^{1}$ The project obtains insulin that would otherwise be destroyed and has distributed 63000 vials to countries in every continent. ${ }^{2}$ I would encourage readers to consider establishing similar programmes, as has been done in New Zealand; those who are interested may contact me for more information. There are also many advantages in having a humanitarian medical supply project integrated with an international medical centre rather than separate from it, and we would encourage other such centres to consider adopting a similar project.

Lifesaving insulin gets destroyed because of lack of knowledge of nominal expiry dates, and no doubt this also occurs with some other medicines. Practical programmes that allow such medicines to be used would save many lives.

The emergency insulin distribution project is funded entirely by donations. With further donations we would be able to distribute more insulin that would otherwise be destroyed. We would welcome correspondence from individuals and 